\title{
Sonochemical removal of naphthol blue black azo dye: influence of parameters and effect of mineral ions
}

\author{
S. Dalhatou • C. Pétrier · S. Laminsi • \\ S. Baup
}

Received: 4 June 2013/Revised: 9 September 2013/Accepted: 5 November 2013/Published online: 27 November 2013

(C) Islamic Azad University (IAU) 2013

\begin{abstract}
Sonochemical degradation at $278 \mathrm{kHz}$ of naphthol blue black (NBB, a diazo dye widely used in the textile and soap industries) has been investigated. The effects of different parameters and the influence of mineral matrix (bicarbonates ions and phosphates ions) on its sonodegradation have been evaluated. The influence of parameters linked to the pollutant (concentration: $0.50-97.32 \mu \mathrm{mol} \mathrm{L}^{-1}$ ), to the technique (power:

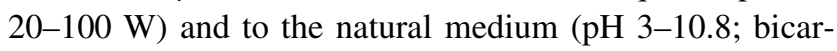
bonate ions; phosphate ions) has been studied. The decolourisation rate of $\mathrm{NBB}$ increases when substrate concentration or ultrasound power increases. Bicarbonate ions at natural medium concentration $\left(2.97 \mathrm{mmol} \mathrm{L}^{-1}\right)$ have a positive influence for low pollutant concentration (0.5-2.0 $\left.\mu \mathrm{mol} \mathrm{L}^{-1}\right)$, due to carbonate radicals. Phosphate ions may also improve the kinetics, but this effect depends on the $\mathrm{pH}$ domains. Furthermore, acid $\mathrm{pH}(\mathrm{pH} 3)$ has a positive effect for high pollutant concentration, whereas basic $\mathrm{pH}(\mathrm{pH} 10.8)$ has a positive influence at low pollutant concentration.
\end{abstract}

Electronic supplementary material The online version of this article (doi:10.1007/s13762-013-0432-8) contains supplementary material, which is available to authorized users.

S. Dalhatou · C. Pétrier · S. Baup ( $\square)$

Laboratoire Rhéologie et Procédés, Univ. Joseph Fourier UJF, Grenoble-INP, CNRS, 363 Rue de la Chimie, BP 53,

38041 Grenoble Cedex 9, France

e-mail: stephane.baup@ujf-grenoble.fr

S. Dalhatou $\cdot$ S. Baup

LEPMI, Grenoble-INP, UJF, CNRS, 1130 Rue de la Piscine, BP 75, 38402 Grenoble, France

S. Dalhatou · S. Laminsi

Laboratoire de Chimie Minérale, Faculté de Sciences,

Université de Yaoundé I, BP 812, Yaoundé, Cameroon
Keywords Naphthol blue black · Azo dye · Ultrasound · Sonochemistry $\cdot$ Bicarbonates ions $\cdot$ Phosphate ions

\section{Introduction}

Coloured wastewater from many industries is a problem in large parts of the world. Due to their relatively high solubility, synthetic dyes are common water pollutants and are likely to be frequently found in industrial wastewater as trace quantities (Crini 2006). The release of those coloured wastewaters in environment is a considerable source of non-aesthetic pollution, eutrophication and chemical reactions, namely oxidation, hydrolysis, complexation and precipitation that take place in the aqueous phase. They are likely to generate metabolites, which are much more toxic than the parent pollutant (Neppolian et al. 2002).

Azo dyes are synthetic organic chemicals widely used in textile, pulp and paper, plastic, pharmaceutical, food, paint and other industries. They are characterized by the presence of at least one nitrogen-to-nitrogen double bond $(-\mathrm{N}=\mathrm{N}-)$ bearing aromatic rings, and they dominate the worldwide market of dyestuff with a share of about $70 \%$ (Soares et al. 2002). Furthermore, some azo dyes and their dye precursors have been proven or are suspected to be human carcinogens as they generate toxic aromatic amines (Stylidi et al. 2003). Therefore, colour removal has drawn an increasing attention of scientists, as indicated by the multitude of related research reports.

Many physical and chemical methods including adsorption, coagulation, ultrafiltration, reverse osmosis, membrane process and biological treatment have been used for the treatment of azo dyes (Latif et al. 2010). Nevertheless, they are non-destructive techniques since they just transfer organic pollutants from water to another phase, 
thus causing secondary pollution (retentate, sludge, adsorbent, etc.).

Among the advanced oxidation process (AOP), degradation of dye using high-frequency ultrasound has gained interest in recent years and some articles devoted to this topic have been previously reported by Özen et al. (2005). It is expected that the application of an ultrasound system to degrade the dye shows lots of advantages because this technique prevents the transfer of the pollutant from one part of environment to another, operates at ambient conditions and does not require the addition of any extra chemicals or catalysts (Kritikos et al. 2007).

This process is based on ${ }^{\circ} \mathrm{OH}$ radical production mainly through the acoustic cavitation, which is defined as the cyclical formation (nucleation), rapid growth (expansion) and collapse (implosion) of microbubbles in the liquid (Crum 1995; Suslick 1990). Fast collapse of the bubbles adiabatically compresses entrapped gas and vapour, which results in short and local hot spots according to Fitzgerald et al. (1956). At the final step of the collapse, the temperature and pressure inside the residual bubble or in the surrounding liquid are thought to be above $2,000 \mathrm{~K}$ and 500 bars, respectively. In this situation, entrapped molecules of dissolved gases, vaporized water and solutes can be brought to an excited state and dissociate. In particular, water and oxygen molecules undergo thermal dissociation and can generate ${ }^{\circ} \mathrm{OH}$ and ${ }^{\circ} \mathrm{OOH}$ radicals (Eqs. 1, 2) (Mason and Pétrier 2004). These primary radicals of sonolysis can react in three different zones: in the gas phase, at the cavitation bubble interface (recombination and formation of hydrogen peroxide, Eqs. 3, 4) and in the solution bulk (formation of hydrogen peroxide and initiation of oxidation reactions of pollutant P, Eq. 5) (David 2009).

$$
\begin{aligned}
& \left.\left.\left.\mathrm{H}_{2} \mathrm{O}+\right)\right)\right) \rightarrow{ }^{\bullet} \mathrm{H}+{ }^{\bullet} \mathrm{OH} \\
& \bullet \mathrm{H}+\mathrm{O}_{2} \rightarrow \bullet \cdot \mathrm{OOH} \\
& 2^{\bullet} \mathrm{OH} \rightarrow \mathrm{H}_{2} \mathrm{O}_{2} \quad k=5.5 \times 10^{9} \mathrm{~L} \mathrm{~mol}^{-1} \mathrm{~s}^{-1} \\
& 2^{\bullet} \mathrm{OOH} \leftrightarrow \mathrm{H}_{2} \mathrm{O}_{2}+\mathrm{O}_{2} \\
& \mathrm{P}+{ }^{\bullet} \mathrm{OH} \rightarrow \text { by-product }
\end{aligned}
$$

The chemical pathway and the rate of elimination depend on the volatility, hydrophobicity and surface activity of the pollutant (Hoffmann et al. 1996). A volatile and hydrophobic molecule will be incinerated inside the bubble of cavitation, while a non-volatile and hydrophilic molecule will be oxidized by the ${ }^{\circ} \mathrm{OH}$ radicals ejected from the cavitation bubble (Hoffmann et al. 1996; Pétrier et al.
1998). Finally, non-volatile and hydrophobic molecule will undergo mainly radical attacks at the cavitation bubble interface (Ashokkumar et al. 1997, 1999; Barbour et al. 1999).

Inorganic anions such as bicarbonate ions are usually present in industrial and natural waters. It is reported in literature that the bicarbonate ions in pollutant wastewater have negative effect on several $\mathrm{AOPs}: \mathrm{TiO}_{2}$ photocatalysis, photo-Fenton, UV/ $\mathrm{H}_{2} \mathrm{O}_{2}, \mathrm{UV} / \mathrm{O}_{3}$ (Neppolian et al. 2002; Pignatello et al. 2006; Guittonneau et al. 1986; Tanaka et al. 2001). Nevertheless, their effects on sonochemical water treatment processes are controversial. Some papers have shown that the presence of bicarbonate ions does not affect appreciably the sonochemical elimination of organic pollutant (Cost et al. 1993; Gültekin et al. 2008), while other papers have provided evidence that sonolysis of organic substrates can be accelerated by the presence of inorganic anions (Guzman-Duque et al. 2011; Chiha et al. 2011; Minero et al. 2008).

In this study, in order to investigate the sonochemical degradation of dyes, a diazo dye naphthol blue black (NBB) has been chosen as a pollutant model. The effects of some parameters on the sonochemical decolourisation of NBB were evaluated: NBB concentration, ultrasonic power and $\mathrm{pH}$. Therefore, the influence of inorganic species, such as bicarbonates ions, found abundantly in natural water and wastewater, was studied. Finally, the mineralization degree of NBB using ultrasound has been examinated by TOC measurement. This research was conducted both at the University of Grenoble and the University of Yaounde, from October 2011 to March 2013.

\section{Materials and methods}

\section{Chemicals}

Naphthol blue black (NBB) was supplied by SigmaAldrich Corporation and used without any purification. Potassium iodide (KI) and ammonium heptamolybdate $\left(\mathrm{NH}_{4}\right)_{6} \mathrm{Mo}_{7} \mathrm{O}_{24}, 4 \mathrm{H}_{2} \mathrm{O}$ come, respectively, from Acros Organics and Chimie Plus. Sodium bicarbonate was purchased from Prolabo, as $\mathrm{H}_{3} \mathrm{PO}_{4}, \mathrm{NaH}_{2} \mathrm{PO}_{4}, \mathrm{Na}_{2} \mathrm{HPO}_{4}$ and $\mathrm{Na}_{3} \mathrm{PO}_{4}$, to test phosphate effect.

The water used to prepare solutions and clean the reactor and glassware was purified with activated carbon cartridges and then deionized thanks to ion exchange resins, from Fisher Bioblock Scientific. 
Apparatus

The power system is a high-frequency generator (Radiocoms Systèmes ULV300A), which delivers a $278 \mathrm{kHz}$ frequency. The impedance of this generator is set at $50 \Omega$ and regulated by an impedance adapter. At the base of the reactor, a piezoelectric disc is fixed (diameter $4 \mathrm{~cm}$ ) on a Pyrex plate ( $5 \mathrm{~cm}$ diameter) the role of which is to transmit the ultrasonic waves in the solution to be treated.

The cylindrical reactor $(400 \mathrm{~mL})$ is double-jacketed in order to maintain the system at a constant temperature $\left(20 \pm 1{ }^{\circ} \mathrm{C}\right)$ to avoid thermal fluctuation induced by ultrasound. Temperature is monitored thanks to a thermocouple immersed in the solution. The cooling water is cooled by a cryostat (Heto CB 8-30e).

\section{Analysis}

Quantitative analysis of NBB was performed by UV-visible spectroscopy thanks to a Shimadzu UV-mini 1240 spectrophotometer, set at a $618 \mathrm{~nm}$ wavelength. For an experiment, about 10 samples (each of them of $1.5 \mathrm{~mL}$ ) are regularly withdrawn to be analysed.

A Shimadzu TOC-Vcsn analyser was used for total organic carbon (TOC) measures. The instrument was equipped with an automatic sample injector (ASI Oct 1-8). A solution of potassium phthalate was used as the calibration standard. Acidification and stripping were carried out before analyses.

$\mathrm{H}_{2} \mathrm{O}_{2}$ concentration is analytically determined by the spectrophotometric method, using potassium iodide $\left(1 \mathrm{~g} \mathrm{~L}^{-1}\right)$ and ammonium heptamolybdate salt as catalyst $\left(10^{-4} \mathrm{~mol} \mathrm{~L}{ }^{-1}\right)$. Aliquots $(1 \mathrm{~mL})$ were taken from the reactor and were immediately added in the sample quartz bowl of the Shimadzu UV-mini 1240 spectrophotometer containing the reagents. Absorbance at a $350 \mathrm{~nm}$ wavelength was recorded after $5 \mathrm{~min}$.

Experimental work

This work is devoted to the sonodegradation of naphthol blue black. Kinetics of sonodegradation was conducted in order to examine the influence of operating parameters, including pollutant initial concentration, power and pH. It also studies the presence of two different mineral ions, bicarbonate and phosphate, likely to be present in natural waters. Finally, TOC measurements were carried out in order to estimate the mineralization of the pollutant.

\section{Results and discussion}

\section{Effect of concentration}

When submitting a solution of NBB to ultrasound at $278 \mathrm{kHz}$, its concentration decreases exponentially as a function of the irradiation time (Fig. 1). This decrease can be expressed by Eq. (6) derived from a first-order kinetics.

$C=C_{0} \exp (-k t)$

where $C_{0}$ is the initial concentration of pollutant, $C$ is the concentration at the irradiation time $t$ and $k$ represents the rate constant of the first-order kinetics.

In parallel to the process of sonodegradation of NBB, hydrogen peroxide is formed in the solution, at a slightly lower rate than that of distilled water without any chemical target (Fig. 1). It is clear that in the absence of any substrate, the radical species $\left({ }^{\bullet} \mathrm{OH}\right.$ and $\left.{ }^{\bullet} \mathrm{OOH}\right)$ formed in the cavitation bubble recombine at the interface bubble/
Fig. 1 Sonochemical degradation kinetics of NBB and comparison of $\mathrm{H}_{2} \mathrm{O}_{2}$ production in absence (square) and in presence (triangle) of NBB. $[\mathrm{NBB}]_{0}: 8.1 \mu \mathrm{mol} . \mathrm{L}^{-1}$, frequency: $278 \mathrm{kHz}$, power: $100 \mathrm{~W}$, volume: $400 \mathrm{~mL}$, temperature: $20 \pm 1{ }^{\circ} \mathrm{C}$

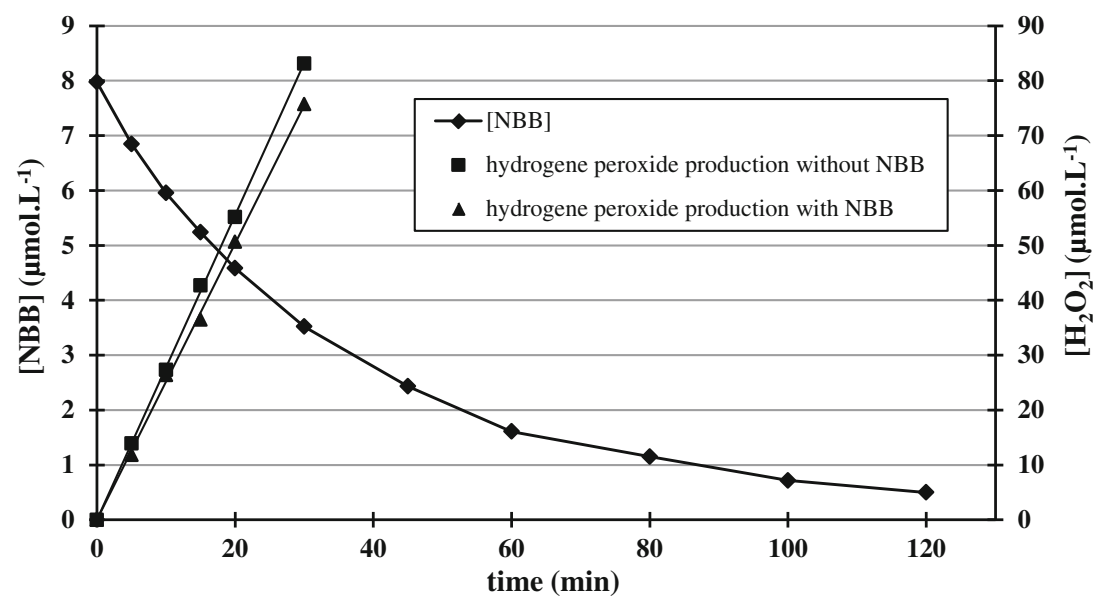


solution to produce hydrogen peroxide, which is then ejected into the solution (Eqs. 3, 4).

The NBB is very soluble in water and nonvolatile. Therefore, its degradation takes place in solution via hydroxyl radicals attacks. Given the very short lifetime of these ${ }^{\circ} \mathrm{OH}$ radicals (about $70 \mathrm{~ns}$, Haugland 1996), it is clear that only a small amount could not recombine and is ejected into the solution. There, those radicals react with the pollutant molecules and more specifically near the interface. Méndez-Arriaga et al. (2008) gradually added quantities of $\mathrm{H}_{2} \mathrm{O}_{2}$ equivalent to those produced by sonolysis in a solution of ibuprofen, mechanical stirred and in the absence of ultrasound. They found that there was no degradation of the pollutant, so hydrogen peroxide is not responsible for the ibuprofen sonochemical degradation, but the ${ }^{\bullet} \mathrm{OH}$ at the bubble-solution interface are.

In our case, the same experiment as that of MéndezArriaga et al. (2008) was performed with a solution of NBB $\left(8.1 \mu \mathrm{mol} \mathrm{L}{ }^{-1}\right)$. In accordance with their results, it is shown that there is no influence of $\mathrm{H}_{2} \mathrm{O}_{2}$ on the oxidation rate of NBB (Fig. 1). Under these conditions, the hydrogen peroxide does not play any significant part, which means it would not cause the decolourisation of NBB solution. This action is attributed to ${ }^{\circ} \mathrm{OH}$.

Figure 2 shows the evolution of the initial rate of the NBB decolourisation, $V_{\mathrm{i}}$, depending on the NBB initial concentration $C_{0}$. At low concentration $\left(C_{0}<8.1 \mu \mathrm{mol} \mathrm{L}^{-1}\right)$, it is noticed that the dependence of $V_{\mathrm{i}}$ on $C_{\mathrm{i}}$ is linear, reflecting a first-order kinetics (Luo and Hepel 2001). However, at high concentrations $\left(C_{0}>32.44 \mu \mathrm{mol} \mathrm{L}{ }^{-1}\right)$, the rate increases slightly, indicating the nature of uninsulated sonochemical reactions with the NBB. Also, this behaviour reflects the combined effects of by-products and oxidizing species generated in the solution, as radical species and by-products are known for their competition to react with ${ }^{\bullet} \mathrm{OH}$ (Méndez-

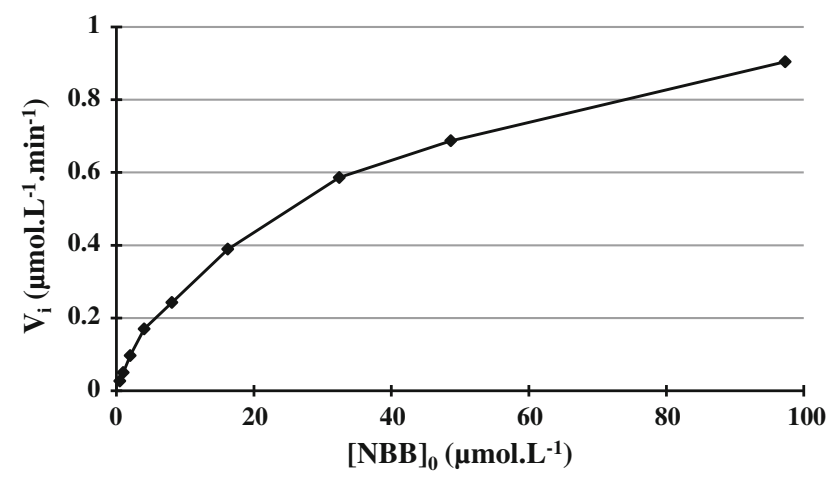

Fig. 2 Influence of initial concentration on initial rate of NBB sonochemical decolourisation. Frequency: $278 \mathrm{kHz}$, power: $100 \mathrm{~W}$, volume: $400 \mathrm{~mL}$, temperature: $20 \pm 1{ }^{\circ} \mathrm{C}$
Arriaga et al. 2008). For the whole concentration range $\left.(0.50-97.32 \mu \mathrm{mol} \mathrm{L})^{-1}\right)$, the results show that the initial rate $V_{\mathrm{i}}$ increases with the initial concentration $C_{\mathrm{i}}$.

However, the kinetic model of such a reaction established by several authors is the controversial subject. Some of them have argued that the degradation of pollutants does not follow first-order kinetics (Torres et al. 2008; Serpone et al. 1994). To test the hypothesis of a first-order kinetics, our results were analysed by applying the Langmuir kinetics law (Eq. 7) and its corresponding linear form (Eq. 8) as follows:

$V_{\mathrm{i}}=\frac{K^{\prime} K C_{\mathrm{i}}}{1+K C_{\mathrm{i}}}$

$\frac{1}{V_{\mathrm{i}}}=\frac{1}{k^{\prime} K C_{\mathrm{i}}}+\frac{1}{K^{\prime}}$

where $V_{\mathrm{i}}$ is the initial rate, $C_{\mathrm{i}}$ the initial concentration, $k^{\prime}$ and $K$ are the rate constant and the equilibrium constant, respectively, deduced from the intercept and the slope.

The respective values of $k^{\prime}$ and $K$ are $0.73 \mu \mathrm{mol} \mathrm{L}^{-1-}$ $\min ^{-1}$ and $7.62 \times 10^{-2} \mu \mathrm{mol} \mathrm{L}^{-1}$ (Fig. 3). This kinetic model is similar to the Langmuir type, so the first order, that is in agreement with those reported in the literature (Luo and Hepel 2001). In addition, the NBB is very soluble in water (hydrophilic), and then, sonodegradation occurs mainly in the bulk of the solution. So some models based on a simultaneous degradation of the pollutant at the interface bubble/solution and in the solution cannot be applied, like the kinetic model proposed by Serpone et al. (1994).

\section{Effect of power}

From an economic perspective and in order to take into account the energetic cost, power is the most important

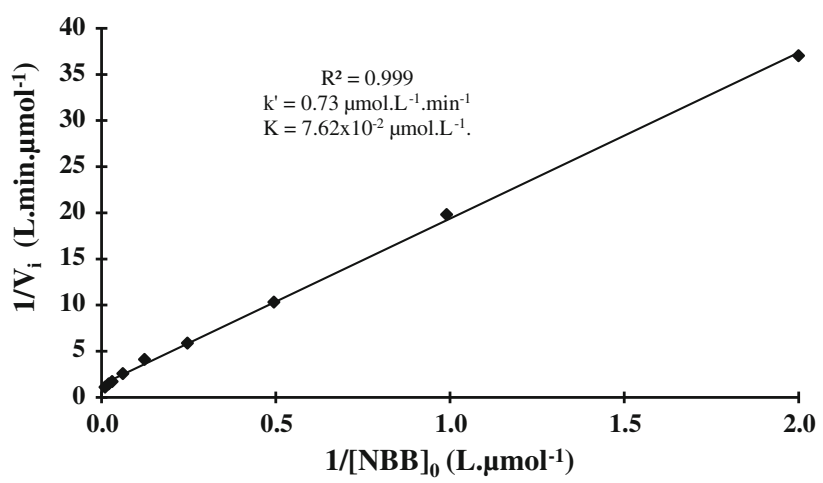

Fig. 3 Langmuir relationship between initial rate of NBB sonochemical decolourisation and initial concentration. $[\mathrm{NBB}]_{0}=$ $0.5-97.3 \mu \mathrm{mol} \mathrm{L}^{-1}$, frequency: $278 \mathrm{kHz}$, power: $100 \mathrm{~W}$, volume: $400 \mathrm{~mL}$, temperature: $20 \pm 1{ }^{\circ} \mathrm{C}$ 


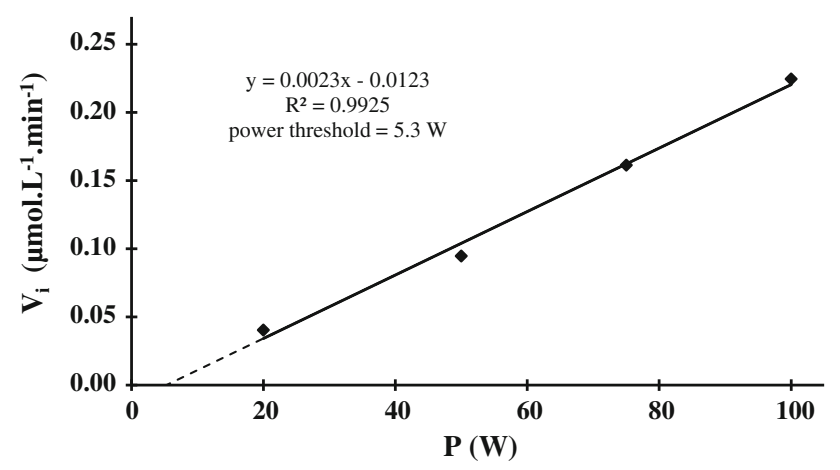

Fig. 4 Effect of power on the initial rate of NBB decolourisation. $[\mathrm{NBB}]_{0}=8.1 \mu \mathrm{mol} \mathrm{L}{ }^{-1}$, frequency: $278 \mathrm{kHz}$, volume: $400 \mathrm{~mL}$, temperature: $20 \pm 1{ }^{\circ} \mathrm{C}$

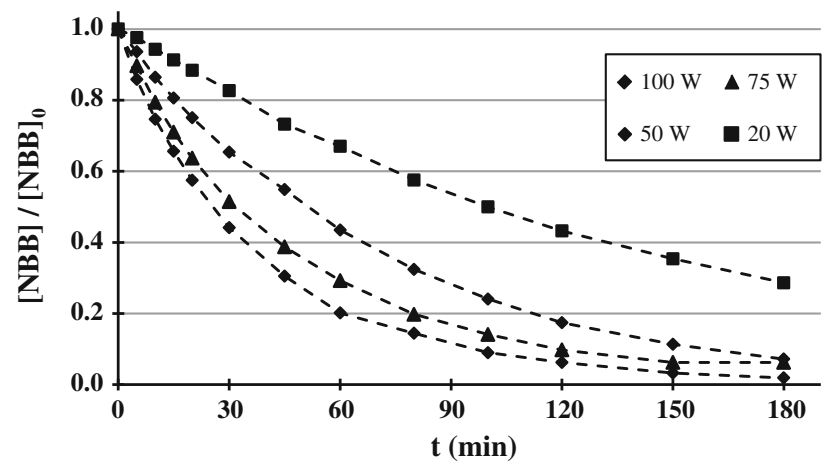

Fig. 5 Effect of power on the NBB sonochemical decolourisation. $[\mathrm{NBB}]_{0}=8.1 \mu \mathrm{mol} \mathrm{L}{ }^{-1}$, frequency: $278 \mathrm{kHz}$, volume: $400 \mathrm{~mL}$, temperature: $20 \pm 1{ }^{\circ} \mathrm{C}$

criterion for choosing a water treatment technique. In sonochemistry, power is one of the parameters responsible for the molecular activation.

At an operating frequency of $278 \mathrm{kHz}$, different ultrasonic powers $(20,50,75$ and $100 \mathrm{~W})$ were applied. The calorimetric method (Mason et al. 1992) used to measure the power dissipated in the reactor reveals a yield of $58.5 \pm 5.3 \%$.

Figure 4 shows to the decolourisation rate as a function of the applied power. For the power range studied, the decolourisation rate of sonochemical NBB increases linearly with the applied power. This linear dependence of the initial rate of sonochemical degradation versus power has been also reported for other chemicals (Hung et al. 2000). However, the power range is studied in an interval between the cavitation threshold and a maximum power value. Above the maximum power, the sonochemical effects are attenuated (Floger and Barnes 1968) and it is reported that no reaction is observed below the cavitation threshold, which is obtained for a $5.3 \mathrm{~W}$ power in our case (Fig. 4).

The effect of power on the degradation rate can be explained by the relationship between the activity of cavitation and the power. Generally, the ultrasonic power affects the cavitation by increasing the population of bubbles, resulting in an increase in ${ }^{\circ} \mathrm{OH}$ as shown by Henglein (1987). As a consequence, the power thanks to the main degradation mechanism (radical attacks) will have a direct impact on the degree of conversion of NBB, as highlighted by Fig. 5 (Jiang et al. 2006).

Influence of mineral ions

\section{Effect of bicarbonate}

The physicochemical analyses of water have often revealed the presence of mineral ions, including ions $\mathrm{HCO}_{3}{ }^{-}$with levels depending on the nature of the effluent, and the site where the samples are carried out, as mentioned by Chiha et al. (2011). The inhibitory effect of bicarbonate ions on several advanced oxidation processes is well known (Neppolian et al. 2002; Pignatello et al. 2006; Guittonneau et al. 1986; Tanaka et al. 2001; Chen et al. 1997). However, its role in the treatment of these effluents by ultrasound is ambiguous, with contradictory data reported in literature. Recently, some works highlighting the accelerating effect of bicarbonates on the sonodegradation of recalcitrant pollutants at low concentrations were published, for instance by Guzman-Duque et al. (2011).

To have a better understanding of the influence of bicarbonate ions in aqueous medium, solutions of NBB in the presence and in the absence of $\mathrm{HCO}_{3}{ }^{-}$were submitted

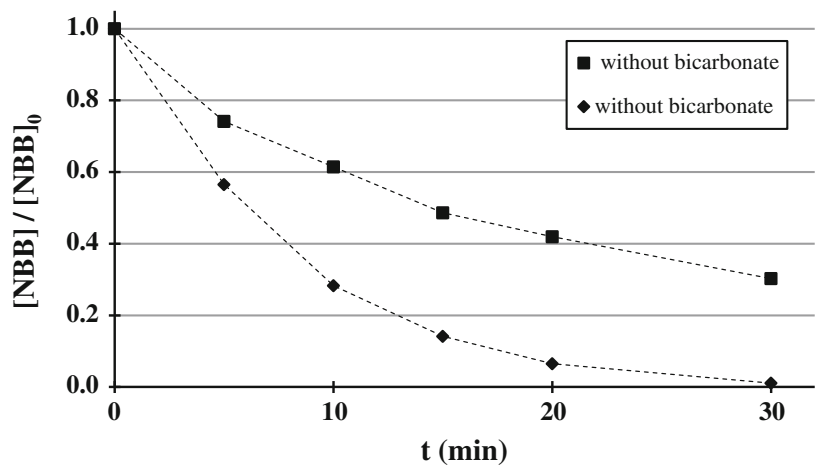

Fig. 6 Effect of bicarbonate ions on the sonochemical decolourisation of NBB (without square and with bicarbonates diamond (250 mg L $\left.{ }^{-1}\right)$; $[\mathrm{NBB}]_{\mathrm{o}}=2 \mu \mathrm{mol} \mathrm{L}{ }^{-1}$; frequency: $278 \mathrm{kHz}$, power: $100 \mathrm{~W}$, volume: $400 \mathrm{~mL}$, temperature: $20 \pm 1{ }^{\circ} \mathrm{C}$ ) 
to ultrasound. The $250 \mathrm{mg} \mathrm{L}^{-1}$ bicarbonate concentration used is not only in the optimal range of concentration values (Guzman-Duque et al. 2011), but is also mainly found in natural waters (Merouani et al. 2010).

Comparative kinetics of NBB sonochemical decolourisation were performed, in the absence and the presence of bicarbonate ions as a function of substrate concentration. They clearly put in evidence that the presence of $\mathrm{HCO}_{3}{ }^{-}$ ions increases the rate of decolourisation of $\mathrm{NBB}$, only for low initial NBB concentrations, $2 \mu \mathrm{mol} \mathrm{L}{ }^{-1}$ for instance (Fig. 6). At $0.5 \mu \mathrm{mol} \mathrm{L}{ }^{-1}$, decolourisation rate of the NBB is four times faster in the presence of $\mathrm{HCO}_{3}{ }^{-}$that in the absence. When the initial substrate concentration increases, the effect of bicarbonate ions decreases and appears to stabilize at $32.44 \mu \mathrm{mol} \mathrm{L}{ }^{-1}$ (Table 1). This result agrees with previous work in which the inhibitory effect of bicarbonate ions for high concentrations of the pollutant has been shown (Merouani et al. 2010).

Indeed bicarbonate ions are well known for their inhibitory effect on hydroxyl radicals, they react with them in the cavitation bubble to produce radical bicarbonates, which will migrate towards the bulk solution. Even if they are less reactive than ${ }^{\circ} \mathrm{OH}$ radicals $(2.8 \mathrm{~V}), \mathrm{CO}_{3}^{\bullet-}$ radicals are oxidant enough $(1.78 \mathrm{~V})$, more stable and more mobile (Guzman-Duque et al. 2011), which allows them to react with the hydrophilic NBB molecules in the bulk of the solution, hence increasing its rate of decolourisation (Eqs. 9, 10, 11).

$$
\begin{aligned}
& \mathrm{CO}_{2}+\mathrm{HO}^{-} \rightleftarrows \mathrm{HCO}_{3}^{-} \\
& \mathrm{HCO}_{3}^{-}+{ }^{\bullet} \mathrm{OH} \rightarrow \mathrm{CO}_{3}^{\bullet-}+\mathrm{H}_{2} \mathrm{O} \mathrm{k} \\
& =8.5 \times 10^{6} \mathrm{~L} \mathrm{~mol}^{-1} \mathrm{~s}^{-1} \\
& \mathrm{CO}_{3}^{\bullet-}+\mathrm{P} \rightarrow \cdots \rightarrow \text { Products }
\end{aligned}
$$

\section{Effect of phosphate}

To evaluate the influence of phosphate on NBB sonodegradation, solutions of $\mathrm{NBB}\left(8.1 \mu \mathrm{mol} \mathrm{L}{ }^{-1}\right)$ were irradiated, with a $\mathrm{pH}$ ranging from 3 to $10 . \mathrm{pH}$ was adjusted by addition of $\mathrm{H}_{3} \mathrm{PO}_{4}, \quad \mathrm{NaH}_{2} \mathrm{PO}_{4}, \quad \mathrm{Na}_{2} \mathrm{HPO}_{4}$ et $\mathrm{Na}_{3} \mathrm{PO}_{4}$ ( $3 \mathrm{mmol} \mathrm{L}^{-1}$ ) and, according to the $\mathrm{pH}$ value, different anionic species are predominant: $\mathrm{H}_{2} \mathrm{PO}_{4}{ }^{-}, \mathrm{HPO}_{4}{ }^{2-}$ or $\mathrm{PO}_{4}{ }^{3-}$.

As a result, the rate constant is influenced by the phosphate presence according to the $\mathrm{pH}$ (Fig. 7). Maximum effect is obtained at $\mathrm{pH} 3.1$ and $\mathrm{pH} 8$, with a corresponding rate constant of 0,039 and $0,038 \mathrm{~min}^{-1}$, respectively.

In presence of anionic phosphate species, the ${ }^{\bullet} \mathrm{OH}$ radicals, created during ultrasound irradiation, are involved in a

\begin{tabular}{|c|c|c|c|c|c|c|c|c|}
\hline$[\mathrm{NBB}]_{0}\left(\mu \mathrm{mol} \mathrm{L}^{-1}\right)$ & 0.5 & 1 & 2.02 & 4.05 & 8.1 & 16.22 & 32.44 & 48.66 \\
\hline$V_{\mathrm{i}}$ with $\mathrm{HCO}_{3}^{-} / V_{\mathrm{i}}$ without $\mathrm{HCO}_{3}^{-}$ & 4.35 & 3.40 & 2.40 & 1.43 & 1.42 & 1.25 & 1.17 & 1.06 \\
\hline
\end{tabular}
set of four Eqs. (12-15). Thus, phosphate radicals are produced, as reported by Jiang et al. (2002b): $\mathrm{H}_{2} \mathrm{PO}_{4}^{\bullet}, \mathrm{HPO}_{4}^{-\bullet}$

Table 1 Ratio between initial rate of sonochemical decolourisation of NBB in presence and in absence of bicarbonates $\left(250 \mathrm{mg} \mathrm{L}^{-1}\right)$

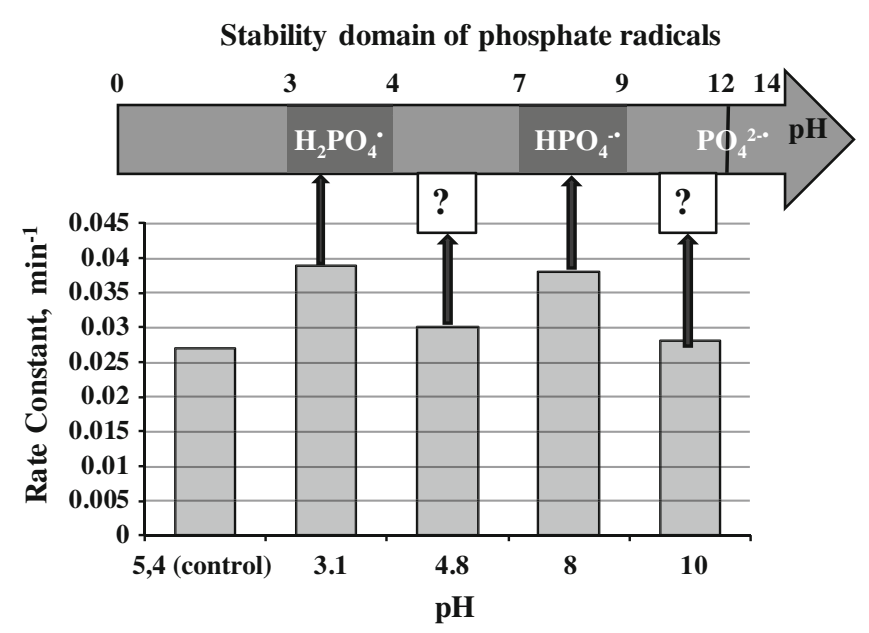

Fig. 7 Effect of phosphate ions on the sonochemical decolourisation of $\mathrm{NBB}$ according to the $\mathrm{pH}$. $[\mathrm{NBB}]_{0}=8.1 \mu \mathrm{mol} \mathrm{L}^{-1}$; $\left[\mathrm{H}_{2} \mathrm{PO}_{4}{ }^{3-}\right]=\left[\mathrm{HPO}_{4}{ }^{2-}\right]=\left[\mathrm{PO}_{4}{ }^{3-}\right]=3 \mathrm{mmol} \mathrm{L}^{-1}$; frequency: $278 \mathrm{kHz}$, power: $100 \mathrm{~W}$, volume: $400 \mathrm{~mL}$, temperature: $20 \pm 1{ }^{\circ} \mathrm{C}$ 
and $\mathrm{PO}_{4}^{2-\bullet}$, corresponding to 3 stability $\mathrm{pH}$ zones respectively 3-4, 7-9 and 12 (Maruthamutu and Neta 1977).

Lifetime of phosphate radicals is about some millisecond (Rosso et al. 1998) while lifetime of hydroxyl radicals is very shorter (about $70 \mathrm{~ns}$ ), so phosphate radicals are more stable. In the literature, these radicals were mentioned to react on organic and inorganic pollutants (Eq. 16), with the following efficiency: $\mathrm{H}_{2} \mathrm{PO}_{4}^{\bullet}>\mathrm{HPO}_{4}^{-\bullet}>\mathrm{PO}_{4}^{2-\bullet}$ (Maruthamutu and Neta 1978).

$$
\begin{aligned}
& \mathrm{H}_{3} \mathrm{PO}_{4}+\mathrm{HO}^{\bullet} \rightarrow \mathrm{H}_{2} \mathrm{PO}_{4}^{\bullet}+\mathrm{H}_{2} \mathrm{O} \\
& \mathrm{H}_{2} \mathrm{PO}_{4}^{-}+\mathrm{HO}^{\bullet} \rightarrow \mathrm{H}_{2} \mathrm{PO}_{4}^{\bullet}+\mathrm{HO}^{-} \\
& \mathrm{HPO}_{4}^{2-}+\mathrm{HO}^{\bullet} \rightarrow \mathrm{HPO}_{4}^{-}+\mathrm{HO}^{-} \\
& \mathrm{PO}_{4}^{3-}+\mathrm{HO}^{\bullet} \rightarrow \mathrm{PO}_{4}^{2-\bullet}+\mathrm{HO}^{-} \\
& \mathrm{X}^{\bullet}+\mathrm{NBB} \rightarrow \cdots \rightarrow \text { Products }
\end{aligned}
$$

$\mathrm{pH} 3.1$ and $\mathrm{pH} 8$ belong to the stability domain of the most oxidant radicals, $\mathrm{H}_{2} \mathrm{PO}_{4}^{\bullet}$ and $\mathrm{HPO}_{4}^{-\bullet}$, respectively 3-4 and $7-9$. So, these radicals improve the kinetics of sonode-

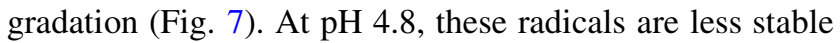
so the rate constant is lower than at $\mathrm{pH} 3.1$ and $\mathrm{pH}$ 8. At $\mathrm{pH}$ 10 , there are no stable phosphate radicals, so the rate constant is low.

Finally, phosphate ions may have a positive effect on NBB decolourisation thanks to phosphate radicals, but it strongly depends on the $\mathrm{pH}$ and the stability domains of these secondary radicals.

\section{Effect of $\mathrm{pH}$}

In sonochemistry, $\mathrm{pH}$ plays a very important role in the degradation of chemical pollutants, because it changes the physical properties by the ionization of functional groups. Generally, at acidic $\mathrm{pH}$, a hydrophilic pollutant undergoes protonation and therefore increases its hydrophobicity. This protonated form becomes predominant, and its degradation increases under these conditions. On the contrary, in basic medium, the pollutant turns into an ionic form that increases its solubility and finally slows its degradation (Jiang et al. 2002a; Stock et al. 2000).

\section{At high concentration of $N B B$}

The effect of $\mathrm{pH}$ on the sonochemical decolourisation of NBB is first tested at high concentration, namely $8.1 \mu \mathrm{mol} \mathrm{L}{ }^{-1}$ (Fig. 8, right abscissa axis). Decolourisation is more pronounced when the $\mathrm{pH}$ is acidic, and it respects the following order: $\mathrm{pH} 3>\mathrm{pH} 5.4>10.8$.

Furthermore, the molecular size of NBB and the presence of many functional groups in its structure (two sulfonates, amine and hydroxyl attached to the naphthalene) make the highlighting of the $\mathrm{pH}$ effect on the sonochemical degradation more complex. Similarly, the lack of information on its $\mathrm{pKa}$ does not predict its structural form with ease depending on the $\mathrm{pH}$ of the medium. However, the high solubility of NBB provides its decolourisation on the bulk of the solution. At $\mathrm{pH} \mathrm{3,} \mathrm{the} \mathrm{sulphonate} \mathrm{groups}$ undergo protonation, which increases the hydrophobicity of the pollutant. Under these conditions, decolourisation of NBB would take place more rapidly in the vicinity of the bubble-solution interface, thereby increasing its conversion rate. At $\mathrm{pH} \mathrm{10.8,} \mathrm{the} \mathrm{molecule} \mathrm{of} \mathrm{the} \mathrm{NBB} \mathrm{takes} \mathrm{a}$ deprotonated or ionic form, and thus, it becomes more hydrophilic and decolourises less rapidly than in an acid medium.
Fig. 8 Effect of $\mathrm{pH}$ on the sonochemical decolourisation of NBB. $[\mathrm{NBB}]_{\mathrm{o}}=8.1 \mu \mathrm{mol} \mathrm{L}-1$ (closed symbols) or $0.5 \mu \mathrm{mol} \mathrm{L} \mathrm{L}^{-1}$ (open symbols), frequency: $278 \mathrm{kHz}$, power: $100 \mathrm{~W}$, volume: $400 \mathrm{~mL}$, temperature: $20 \pm 1{ }^{\circ} \mathrm{C}$ )

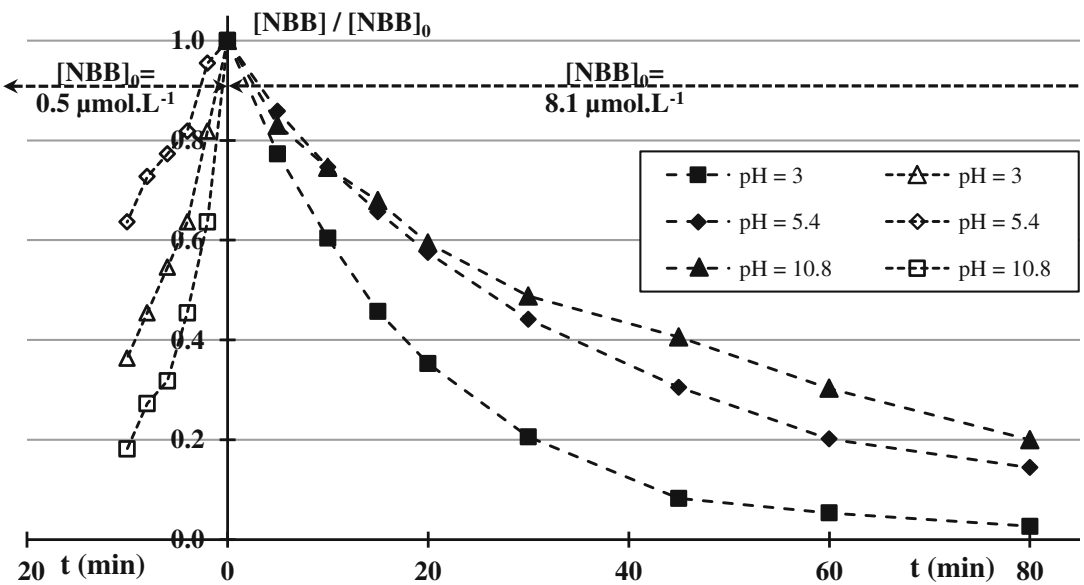




\section{At low concentration of $N B B$}

Contrary to the previous study at high substrate concentration, the order of conversion of NBB at low concentrations $\left(0.5 \mu \mathrm{mol} \mathrm{L}^{-1}\right)$ according to the $\mathrm{pH}$ is the following one: $\mathrm{pH} 10.8>\mathrm{pH} 3>\mathrm{pH} 5.4$ (Fig. 8, left abscissa axis).

The acidic effect ( $\mathrm{pH} 3$ ) on the decolourisation of the pollutant remains unmodified, as previously mentioned for high NBB concentration. Nevertheless, the greatest rate of elimination is obtained at $\mathrm{pH} 10.8$. This behaviour could be explained as follows: at low concentration of NBB and in a basic medium, the dissolved $\mathrm{CO}_{2}$ would not only bicarbonate by reaction with $\mathrm{HO}^{-}$anion as previously mentioned (Eq. 9), but also carbonate (Eq. 17) because the $\mathrm{pH}$ is higher than the $\mathrm{HCO}_{3}{ }^{-} / \mathrm{CO}_{3}{ }^{2-} \mathrm{pK}_{\mathrm{a}}$. So, the radicals $\mathrm{CO}_{3}^{-}$are likely to be obtained through $\mathrm{HCO}_{3}{ }^{-}$ as previously mentioned (Eq. 10) and also through $\mathrm{CO}_{3}{ }^{2-}$ (Eq. 18), the constant of which is 100 times much higher. So, there are more $\mathrm{CO}_{3}^{\bullet-}$ radicals in the basic medium, implying a faster decolourisation in this case.

$$
\begin{aligned}
& \mathrm{HCO}_{3}^{-}+\mathrm{HO}^{-} \rightleftarrows \mathrm{CO}_{3}^{2-}+\mathrm{H}_{2} \mathrm{O} \quad \mathrm{pK}_{\mathrm{a}}=10.3 \\
& \mathrm{CO}_{3}^{2-}+\mathrm{HO}^{\bullet} \rightarrow \mathrm{CO}_{3}^{\bullet-}+\mathrm{HO}^{-} \\
& \mathrm{k}=3.9 \times 10^{8} \mathrm{~L} \mathrm{~mol}^{-1} \mathrm{~s}^{-1}
\end{aligned}
$$

\section{Mineralization of NBB}

The only decolourisation is not enough to talk about the degradation. The mineralization degree of NBB (97.32 $\mu \mathrm{mol} \mathrm{L}^{-1}$ ) by ultrasound was evaluated by measurement of TOC. This is carried out in the following operating conditions: $278 \mathrm{kHz}, 100 \mathrm{~W}$ of electric power and at natural $\mathrm{pH}$ in the presence of air as the saturating gas. Table 2 shows the TOC removal of $19.9 \%$ after 360 min of treatment. It should be noted that hydroxyl radicals and hydrogen peroxide are oxygen species which are responsible for the sonochemical degradation of micropollutants studied. However, an estimated $80 \%$ of the radicals ${ }^{\bullet} \mathrm{OH}$ and $\mathrm{H}^{\bullet}$ generated by sonolysis recombine, and only a small amount of ${ }^{\circ} \mathrm{OH}$ escapes and reacts with organic molecules in solution. The low conversion of TOC obtained confirms that the action of ultrasound on organic pollutants leads to very hydrophilic and low volatile intermediates, which migrate to the bulk of the solution where they degrade easily by ${ }^{\bullet} \mathrm{OH}$ radical attack. During the same period and for similar pollutants, Stock et al. (2000) obtained the same removal rate of TOC
Table 2 TOC removal for NBB sonochemical degradation

\begin{tabular}{lll}
\hline$t(\min )$ & TOC $\left(\mathrm{mg} \mathrm{L}^{-1}\right)$ & TOC removal $(\%)$ \\
\hline 0 & 41.2 & 0 \\
180 & 39.2 & 4.9 \\
360 & 33.0 & 19.9 \\
\hline
\end{tabular}

$[\mathrm{NBB}]_{0}=97.32 \mu \mathrm{mol} \mathrm{L}^{-1}$, frequency: $278 \mathrm{kHz}$, power: $100 \mathrm{~W}$, volume: $400 \mathrm{~mL}$, temperature: $20 \pm 1{ }^{\circ} \mathrm{C}$

$\left(50 \mu \mathrm{mol} \mathrm{L}{ }^{-1}\right)$ after 480 min of ultrasonic irradiation time. However, this study was carried out in different operating conditions $(640 \mathrm{kHz}, 240 \mathrm{~W}$ power supply, $\mathrm{V}=500 \mathrm{~mL}$

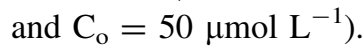

\section{Conclusion}

The sonochemical decolourisation of NBB was studied at $278 \mathrm{kHz}$ in aqueous media. The effects of different parameters have been investigated. It appears that the NBB decolourisation takes place in the bulk of the solution by $\mathrm{OH}$ radical attack, and its rate is influenced significantly by substrate concentration, power supply, $\mathrm{pH}$ and mineral ions. For low concentration of NBB, sonochemical decolourisation is enhanced by bicarbonate ions, due to the formation of carbonate radicals likely to migrate in the bulk of liquid and to attack substrate. Moreover, still at low NBB concentration, the same effect is underlined because the decolourisation rate is improved for basic $\mathrm{pH}$, above the $\mathrm{pK}_{\mathrm{a}}$ of the couple $\mathrm{HCO}_{3}{ }^{-} / \mathrm{CO}_{3}{ }^{2-}$, because $\mathrm{CO}_{3}{ }^{2-}$ is the dominant form of the carbonates species and is a better source of carbonate radicals. Finally, phosphate ions have a positive influence thanks to phosphate radicals, but this effect strongly depends on the $\mathrm{pH}$ and the stability zones of these radicals.

Acknowledgments The authors wish to express their gratitude to the "Service de Coopération et des Actions Culturelles" of the French Embassy to Cameroon for their financial support, corresponding to the Grant No. SCAC 152/2010-81.

\section{References}

Ashokkumar M, Hall R, Mulvaney P, Grieser F (1997) Sonoluminescence from aqueous alcohol and surfactant solutions. J Phys Chem B 101(50):10845-10850 
Ashokkumar M, Mulvaney P, Grieser F (1999) The effect of pH on multibubble sonoluminescence from aqueous solutions containing simple organic weak acids and bases. J Am Chem Soc 121(32):7355-7359

Barbour K, Ashokkumar M, Caruso R, Grieser FJ (1999) Sonochemistry and sonoluminescence in aqueous AuCl4-solutions in the presence of surface-active solutes. Phys Chem B 103(43): 9231-9236

Chen HY, Zahraa O, Bouchy M (1997) Inhibition of the adsorption and photocatalytic degradation of an organic contaminant in an aqueous suspension of $\mathrm{TiO}_{2}$ by inorganic ions. $\mathrm{J}$ Photochem Photobiol A Chem 108(1):37-44

Chiha M, Hamdaoui O, Baup S, Gondrexon N (2011) Sonolytic degradation of endocrine disrupting chemical 4-cumylphenol in water. Ultrason Sonochem 18(5):943-950

Cost M, Mills G, Glisson P, Lakin J (1993) Sonochemical degradation of p-nitrophenol in presence of chemical components of natural waters. Chemosphere 27(9):1737-1743

Crini G (2006) Non-conventional low-cost adsorbents for dye removal: a review. Bioresour Technol 97(9):1061-1085

Crum LA (1995) Comments on the evolving field of sonochemistry by a cavitation physicist. Ultrason Sonochem 2(2):147-152

David B (2009) Sonochemical degradation of PAH in aqueous solution. Part I: monocomponent PAH solution. Ultrason Sonochem 16(2):260-265

Fitzgerald ME, Griffing V, Sullivan J (1956) Chemical effects of ultrasonics- "hot spot" chemistry. J Chem Phys 25(5):926-933

Floger S, Barnes D (1968) Shift in the optimal power input in ultrasonic reaction. Ind Eng Chem Fundam 7(2):222-226

Guittonneau S, De Laat J, Doré M, Duguet JP, Bonnel C (1986) Etude de la dégradation des composés organochlorés volatils par photolyse du $\mathrm{H}_{2} \mathrm{O}_{2}$ en milieu aqueux. Revue des sciences de l'eau 1:53-54

Gültekin I, Ince NH, Nilsun H (2008) Ultrasonic destruction of bisphenol-A: the operating parameters. Ultrason Sonochem 15(4):524-529

Guzman-Duque F, Pétrier C, Pulgarin C, Peñuela G, Torres-Palma RA (2011) Effects of sonochemical parameters and inorganic ions during the sonochemical degradation of crystal violet in water. Ultrason Sonochem 18(1):440-446

Haugland RP (1996) Handbook of fluorescent process and research chemicals, 6th edn. Spencer ed, Eugene, OR, pp 484-493

Henglein A (1987) Sonochemistry: historical developments and modern aspects. Ultrasonics 25(1):6-16

Hoffmann MR, Hua I, Hochemer R (1996) Application of ultrasonic irradiation for the degradation of chemical contaminants in water. Ultrason Sonochem 3(3):163-172

Hung H-M, Ling FH, Hoffman MR (2000) Kinetics and mechanism of the enhanced reductive degradation of nitrobenzene by elemental iron in the presence of ultrasound. Environ Sci Technol 34(9):1758-1763

Jiang Y, Petrier C, Waite TD (2002a) Effect of $\mathrm{pH}$ on the ultrasonic degradation of ionic aromatic compounds in aqueous solution. Ultrason Sonochem 9(3):163-168

Jiang Y, Petrier C, Waite TD (2002b) Kinetics and mechanisms of ultrasonic degradation of volatile chlorinated aromatics in aqueous solutions. Ultrason Sonochem 9(6):317-323

Jiang Y, Petrier C, Waite TD (2006) Sonolysis of 4-chlorophenol in aqueous solution: effects of substrate concentration, aqueous temperature and ultrasonic frequency. Ultrason Sonochem 13(5):415-422
Kritikos DE, Xekoukoulotakis NP, Psillakis E, Mantzavinos D (2007) Photocatalytic degradation of reactive black 5 in aqueous solutions: effect of operating conditions and coupling with ultrasound irradiation. Water Res 41(10):2236-2246

Latif A, Noor S, Sharif QM, Najeebullah M (2010) Different techniques recently used for the treatment of textile dyes effluents: a review. J Chem Soc Pak 32(1):115-124

Luo J, Hepel M (2001) Photoelectrochemical degradation of naphthol blue black diazo dye on $\mathrm{WO}_{3}$ film electrode. Electrochim Acta 46(19):2913-2922

Maruthamutu P, Neta P (1977) Reactions of phosphates radicals with organic compounds. J Phys Chem 81(17):1622-1625

Maruthamutu P, Neta P (1978) Phosphate radicals-spectra, acidbase equilibria, and reactions with inorganic compounds. J Phys Chem 82:710-713

Mason TJ, Pétrier C (2004) Advanced oxidation processes for water and wastewater treatment. In: Parson S (ed) Ultrasound processes. IWA Publishing, London, pp 185-208

Mason TJ, Lorimer JP, Bates DM (1992) Quantifying sonochemistry: casting some light on a 'black art'. Ultrasonics 30(1):40-42

Méndez-Arriaga F, Torres-Palma RA, Pétrier C, Esplugas S, Gimenez J, Pulgarin C (2008) Ultrasonic treatment of water contaminated with ibuprofen. Water Res 42(16):4243-4248

Merouani S, Hamdaoui O, Saoudi F, Chiha M, Pétrier C (2010) Influence of bicarbonate and carbonate ions on sonochemical degradation of Rhodamine B in aqueous phase. J Hazard Mater 175(1-3):593-599

Minero C, Pellizzari P, Maurino V, Pelizzetti E, Vione D (2008) Enhancement of dye sonochemical degradation by some inorganic anions present in natural waters. Appl Catal B 77(3-4):308-316

Neppolian B, Choi HC, Sakthivel S, Arabindoo B, Murugesan V (2002) Solar light induced and $\mathrm{TiO}_{2}$ assisted degradation of textile dye reactive blue 4. Chemosphere 46(8):1173-1181

Özen AS, Aviyente V, Tezcanli-Güyer G, Ince NH (2005) Experimental and modeling approach to decolorization of azo dyes by ultrasound: degradation of the hydrazone tautomer. J Phys Chem A 109(15):3506-3516

Pétrier C, Jiang Y, Lamy M-F (1998) Ultrasound and environment: sonochemical destruction of chloroaromatic derivatives. Environ Sci Technol 32(9):1316-1318

Pignatello JJ, Oliveros E, MacKay A (2006) Advanced oxidation processes for organic contaminant destruction based on the Fenton reaction and related chemistry. Crit Rev Environ Sci Technol 36(1):1-84

Rosso JA, Rodriguez Nieto FJ, Gonzalez MC, Martire DO (1998) Reactions of phosphate radicals with substituted benzenes. J Photochem A Chem 116(1):21-25

Serpone N, Terzian R, Hidaka H, Pelizetti E (1994) Ultrasonic induced dehalogenation and oxidation of 2-, 3- and 4-CP in air equilibrated aqueous media, similarities with irradiated semiconductor particles. J Phys Chem 98(10):2634-2640

Soares GM, Amorim MT, Hrdina R, Costa-Ferreira M (2002) Studies on the biotransformation of novel disazo dyes by laccase. Process Biochem 37(6):581-587

Stock NL, Peller J, Vinodgopal K, Kamat PV (2000) Combinative sonolysis and photocatalysis for textile dye degradation. Environ Sci Technol 34(9):1747-1750

Stylidi M, Kondarides DI, Verykios XE (2003) Pathways of solar light-induced photocatalytic degradation of azo dyes in aqueous $\mathrm{TiO}_{2}$ suspensions. Appl Catal B Environ 40(4):271-286 
Suslick KS (1990) Sonochemistry. Science 247(4949):1439-1445

Tanaka T, Tsuzuki K, Takagi T (2001) Chemical oxidation of organic matter in secondary-treated municipal wastewater by using methods involving ozone, ultraviolet radiation and $\mathrm{TiO}_{2}$ catalyst. Water Sci Technol 43(10):295-302
Torres R, Pétrier C, Combet E, Carrier M, Pulgarin C (2008) Ultrasonic cavitation applied to the treatment of bisphenol A. Effect of sonochemical parameters and analysis of BPA byproducts. Ultrason Sonochem 15(4):605-611 